\title{
Cryo-EM of Helical Polymers at Near-atomic Resolution Yields Many Surprises
}

Edward Egelman

University of Virginia, Charlottesville, Virginia, United States

It was over fifty years ago that the first 3D reconstruction from electron microscopy was published (1), and this happened to be a helical phage tail. It was no accident that this was a helical specimen, and not just because helical polymers are so abundant in biology. From one point of view helical objects are the simplest to reconstruct: a single image of a helical filament may provide all of the information needed for a 3D reconstruction. Fourier-Bessel methods of reconstruction (2) dominated the field for the next 30 years, but now real-space approaches have become the standard (3). With the advent of direct-electron detectors, reaching a near-atomic resolution for helical polymers has become the standard, rather than the exception. For example, we have now re-examined a helical phage tail with 1,000 times more information than what was accomplished in 1968 (4). However, problems in determining the correct helical symmetry can persist even when one reaches a resolution of $\sim 5 \AA$ (5). In addition, the highly anisotropic environment present in thin films prior to vitrification, the compressional forces associated with these thin films, and fluid flow with associated shear, can all impact the structure of the filaments being examined (6-10). I will discuss these problems and potential solutions while giving an overview of some of our own efforts involving everything from viruses infecting hosts living in nearly boiling acid (11-13) to microbial nanowires (14), with stops along the way at bacterial and archaeal flagellar filaments (15) and bacterial and archaeal pili (16). Some common themes emerge from these studies, such as how small changes in sequence can be amplified by very large changes in quaternary structure (17), and this may be an under-appreciated mechanism in evolutionary divergence. Structural studies can also identify deep evolutionary relationships that are not evident in sequence comparisons, due to the fact that protein folds may be highly conserved while the sequences diverge (12).

\section{References}

1. DeRosier DJ \& Klug A (1968) Nature 217:130-134.

2. Klug A, Crick FH, \& Wyckoff HW (1958) Acta Crystallographica 11:199-213.

3. Egelman EH (2000) Ultramicroscopy 85:225-234.

4. Zheng W, Wang F, Taylor NMI, Guerrero-Ferreira RC, Leiman PG, \& Egelman EH (2017) Structure25(9):1436-1441 e1432.

5. Egelman EH (2014) eLife 3:e04969 doi:10.7554/eLife.04969.

6. Armstrong MH, B.-G.; Gomez, S.; Turner, J.; Fletcher, D.A.; Glaeser, R.M. (2020) Biophysical Journalin press.

7. Glaeser RM (2018) Curr Opin Colloid Interface Sci 34:1-8.

8. Glaeser RM \& Han BG (2017) Biophys Rep 3(1):1-7.

9. Galkin VE, Orlova A, \& Egelman EH (2012) Current Biology 22:R96-R101.

10. Galkin VE, Orlova A, Vos MR, Schroder GF, \& Egelman EH (2015) Structure 23(1):173-182.

11. Wang F, Liu Y, Su Z, Osinski T, de Oliveira GAP, Conway JF, Schouten S, Krupovic M, Prangishvili D, \& Egelman EH (2019) Proc Natl Acad Sci U S A 116(45):22591-22597.

12. Liu Y, Osinski T, Wang F, Krupovic M, Schouten S, Kasson P, Prangishvili D, \& Egelman EH (2018) Nature communications 9(1):3360.

13. DiMaio F, Yu X, Rensen E, Krupovic M, Prangishvili D, \& Egelman EH (2015) Science 348:914917.

14. Wang F, et al. (2019) Cell 177(2):361-369 e310. 
15. Egelman EH (2017) Curr Opin Struct Biol 46:31-37.

16. Wang F, et al. (2019) Nat Microbiol 4(8):1401-1410.

17. Egelman EH, Xu C, DiMaio F, Magnotti E, Modlin C, Yu X, Wright E, Baker D, \& Conticello VP (2015) Structure 23(2):280-289. 